\title{
REVIEW
}

\section{Liver X receptors and fat cell metabolism}

\author{
J Laurencikiene and M Rydén
}

Liver X receptors (LXRs) are members of the nuclear receptor family and are present in two isoforms, $\alpha$ and $\beta$, encoded by two separate genes. Originally described in the liver, LXRs have in the last 15 years been implicated in central metabolic pathways, including bile acid synthesis, lipid and glucose homeostasis. Although the vast majority of studies have been performed in non-adipose cells/tissues, results in recent years suggest that LXRs may have important modulatory roles in adipose tissue and adipocytes. Although several authors have published reviews on LXR, there have been no attempts to summarize the effects reported specifically in adipose systems. This overview gives a brief introduction to LXR and describes the sometimescontradictory results obtained in murine cell systems and in rodent adipose tissue. The so far very limited number of studies performed in human adipocytes and adipose tissue are also presented. It should be apparent that although LXR may impact on several different pathways in metabolism, the clinical role of LXR modulation in adipose tissue is still not clear.

International Journal of Obesity (2012) 36, 1494-1502; doi:10.1038/ijo.2012.21; published online 28 February 2012

Keywords: liver X receptor; adipocytes; adipose tissue; metabolism; NR1H3; NR1H2

\section{INTRODUCTION}

Liver $\mathrm{X}$ receptor (LXR) $\alpha$ and $\beta$ are transcription factors belonging to the nuclear receptor (NR) superfamily. ${ }^{1}$ They bind to DNA as heterodimers with retinoid $X$ receptor (RXR) (for a review on $R X R^{2}$ ). Most NRs, including LXRs, are activated by small lipophilic ligands. For LXR, these are cholesterol derivatives termed oxysterols (for review on oxysterols ${ }^{3}$ ). Since their initial discovery in 1995, LXRs have emerged as powerful metabolic regulators in different tissues and cell types. For example, LXRs have been shown to regulate cholesterol, bile acid, triglyceride and glucose homeostasis as well as inflammation and intestinal lipid absorption. In addition, murine studies have demonstrated positive effects of LXR agonists on insulin resistance and atherosclerosis. LXRs have therefore been proposed as attractive pharmacological targets in humans. A caveat in this respect is the complex and sometimes opposing effects of LXR activation in different tissues and species in vitro and in vivo. Although recent reviews have made attempts to integrate and discuss the different physiological processes regulated by LXRs, their focus has primarily been on non-adipose tissues. ${ }^{4-6}$ In this review, we specifically address the role of LXR in adipocytes and adipose tissue, and, where available, compare the data obtained in rodent and human experimental systems. The sometimes-conflicting results obtained by different research groups complicate the interpretation of what LXR does, not only at the cellular but also at the whole-body level.

\section{LXR GENES AND EXPRESSION IN ADIPOSE TISSUE}

LXR $\alpha$ and LXR $\beta$ are coded by the NR1H3 and NR1H2 genes, respectively. At the amino acid level, the two isoforms share about $78 \%$ identity in the DNA- and ligand-binding domains. ${ }^{7}$ In humans, several single nucleotide polymorphisms (SNPs) have been reported in both genes (further discussed below). ${ }^{8-10}$

Both $L X R \alpha$ and $\beta$ are expressed in mature murine and human adipocytes. Although expression of $\operatorname{LXR} \alpha$ is upregulated during fat cell differentiation, LXR $\beta$ is not regulated by adipogenesis. ${ }^{11-13}$ Three different splice variants of LXR ${ }^{1-3}$ have been reported, where the most abundant and active form is the $L X R \alpha 1$ variant, which is present in all tissues expressing LXR $\alpha{ }^{14} \mathrm{LXR} \alpha 2$ is predominantly expressed in human testis and cancer cell lines, and lacks the first 45 amino acids present in LXR $\alpha 1$. LXR $\alpha 3$ is generated through an alternative recognition of a $3^{\prime}$-splice site in exon 6 and lacks 50 amino acids within the ligand-binding domain. Expression of LXR $\alpha 3$ has been reported in human lung, thyroid gland, spleen and cancer cell lines. The levels of different LXR $\alpha$ isoforms in adipose tissue have not yet been reported in the literature.

\section{REGULATION OF LXR ACTIVITY IN ADIPOCYTES}

Upon activation, LXRs bind to DNA at specific sites termed LXR response elements (LXREs) (for review see Viennois et al. ${ }^{4}$, Baranowski et al. $\left.{ }^{6}\right)$. As for other NRs, the activity and DNA binding of LXR is regulated by a complex interaction between ligands, cofactors and post-translational modifications.

\section{Ligands and agonists}

Adipocytes harbor large amounts of nonesterified cholesterola potential source of natural ligands for LXR. ${ }^{15}$ It has therefore been postulated that LXR in adipocytes may be constitutively active. In addition, multiple in vivo and in vitro studies in adipose cells have demonstrated that endogenously expressed LXRs can be further activated by treatments with oxysterols and synthetic LXR agonists. For instance, oxysterol 22(R)-hydroxycholesterol has been shown to induce LXR-responsive genes in differentiated murine 3T3-L1 adipocytes. ${ }^{11,12}$ Two synthetic non-steroidal LXR agonists, T091317 (ref. 16) and GW3965, ${ }^{17}$ have been widely used both in vitro and in vivo. The latter two compounds display similar potencies in activating LXR in adipocytes. ${ }^{18}$ However, T091317 is not LXR selective as it can also act as an agonist for the farnesoid $X$ receptor and pregnane $X$ receptor. ${ }^{19,20}$ As farnesoid $X$ receptor is expressed in 3T3-L1 and murine primary adipocytes, ${ }^{21}$ this could influence the results obtained using T091317 in these cells. In contrast, human adipocytes do not express either farnesoid $X$ receptor or pregnane $\mathrm{X}$ receptor (Laurencikiene, unpublished 
observations). Effects of other synthetic LXR activity-modulating compounds ${ }^{22}$ have not been investigated in fat cells.

The stereoisomeric form of the ligand is obviously important as 22(S)-hydroxycholesterol has been shown to act as an LXR antagonist in 3T3-L1 adipocytes, ${ }^{11}$ confirming that LXR possesses some basal activity in fat cells. In hepatocytes, polyunsaturated fatty acids can also act as antagonists in the induction of the LXRresponse gene sterol regulatory element-binding protein-1 (SREBP-1) (for review see Madsen et $a l_{.}^{23}$ ). However, only indirect evidence suggests that a similar interaction might take place in adipocytes. ${ }^{24}$

\section{Co-factors}

Apart from ligands, transcriptional co-regulators provide the context and pathway specificity for LXR signaling. Several cofactors have been shown to form part of the LXR transcriptional complex (Figure 1). In the ligand-free, repressed, state LXRs associate with NR co-repressor (NCoR) and associate somewhat weaker with silent mediator of retinoic acid receptor and thyroid receptor (SMRT). ${ }^{25,26}$ Although both of these co-repressors have been shown to regulate the activity of PPAR $\gamma$ in 3T3-L1 adipocytes, ${ }^{27}$ their impact on LXR function in fat cells has not been investigated. Small heterodimer partner (SHP), is another repressor of LXR activity, ${ }^{28}$ which can interact with LXR both in the presence and absence of ligand. Transgenic over-expression of SHP under the control of the aP2 promoter resulted in increased body weight, adiposity and propensity to develop diet-induced obesity. ${ }^{29}$ However, the interaction between SHP and LXR has not been investigated in fat cells. Another possible co-repressor regulating LXR activity in human white adipocytes is the cell death-inducing DNA fragmentation factor- $\alpha$-like effector A (CIDEA). CIDEA was recently shown to bind to LXR in in vitro and ex vivo systems and to repress LXR-regulated reporter constructs in $3 \mathrm{~T} 3-\mathrm{L} 1$ cells. $^{30}$

Both LXR isoforms have been shown to co-localize and interact with receptor-interacting protein 140 (RIP140). ${ }^{31,32}$ In non-adipose cells, RIP140 can function both as a co-activator and co-repressor of LXR. In hepatocytes for instance, RIP140 acts as a co-activator of LXR-induced lipogenesis, but as a co-repressor of genes regulating

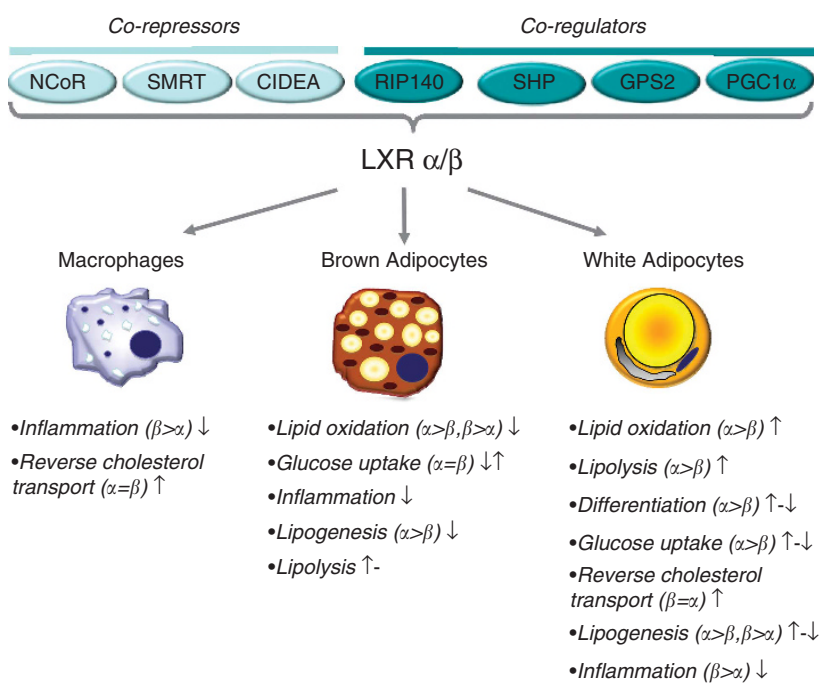

Figure 1. Summary of functions attributed to LXR in different cell types. The proposed role of LXR in different cellular processes are summarized for white and brown adipocytes as well as for macrophages. Where available, information on the main receptor-isoform (that is, $\alpha$ or $\beta$ ) mediating the effect is indicated. Positive ( $\uparrow$ ), negative $(\downarrow)$ or no $(-)$ effects following LXR activation are indicated as reported in the literature. References are given in Table 1. gluconeogenesis. $^{32}$ In brown adipocytes, RIP140 is recruited together with LXR to the enhancer region of Ucp1, encoding Uncoupling protein-1 (UCP1). This interferes with PPAR $\gamma$ binding to the same element and represses UCP1 expression. ${ }^{33}$ PPAR $\gamma$ coactivator $1 \alpha$ (PGC-1 $\alpha)$, a co-activator important for brown adipogenesis, has been shown to potentiate LXR activity in 3T3L1 cells. ${ }^{34}$ In vitro over expression of PGC- $1 \alpha$ enhances liganddependent upregulation of LXRE-driven reporter constructs as well as endogenous expression of the $L X R \alpha$ gene. Recently, a novel coregulator of LXR, G protein pathway suppressor 2 (GPS2), was identified. ${ }^{35,36}$ GPS2 can also function both as a co-activator and co-repressor of LXR. However, there are presently no published data on the role of this co-factor in fat cells. Taken together, LXR can interact with a number of co-regulators that impact on its DNA-binding and transcriptional activity. As most studies in adipocytes have been performed in 3T3-L1 cells, the physiological role of these interactions in primary adipocytes and adipose tissue is not clear.

\section{Post-transcriptional modifications}

The transcriptional activity of LXR and its interaction with co-factor complexes are affected by several post-transcriptional modifications. In hepatocytes, both LXR isoforms are acetylated in the unstimulated, ligand-free state. Upon ligand binding, a conformational change promotes LXR interaction with sirtuin 1 (SIRT1). This leads to de-acetylation at a conserved lysine residue (K432 in LXR $\alpha$ and K433 in LXR $\beta$ ), which promotes the ubiquitination and degradation of the receptor. This implies that activation of LXR promotes increased degradation of the receptor, a common mechanism in NR signaling pathways. In the liver, induction of cholesterol transporters and SREBP-1C by LXR activation is dependent on SIRT1, demonstrating the importance of de-acetylation for LXR function. ${ }^{37}$ In hepatocytes and macrophages, SUMOylation of LXR promotes the interaction with the coregulators NR co-repressor and GPS2. This modification is required for trans-repression of inducible nitric oxide synthases and hepatic acute phase response genes. ${ }^{36,38}$ LXRs can also be phosphorylated by protein kinase $A$ (PKA), which impairs the activation of SREBP-1C transcription in hepatocytes. ${ }^{39}$ Although it is not clear if posttranslational modifications of LXR are present in adipocytes, all three isoforms of SUMO, ${ }^{1-3}$ SIRT1 and protein kinase A are expressed in human fat cells and could therefore possibly regulate LXR activity in adipose tissue.

\section{ROLE OF LXR IN ADIPOGENESIS}

The role of LXR in regulating adipocyte differentiation is still a matter of debate. Different studies have reported stimulation, no effect or even suppression of adipogenesis by LXR ligands. In murine 3T3-L1 cells and human in vitro-differentiated SimpsonGolabi-Behmel syndrome (SGBS) pre-adipocyte cells, LXR expression is regulated by PPAR $\gamma$ and C/EBP $\alpha^{11,13,40,41}$-two transcription factors indispensible for adipogenesis. Functional PPAR $\gamma$-binding elements are present in both the murine and human LXR $\alpha$ gene. ${ }^{41}$ Several stimuli that interfere with adipogenesis, for example, ultraviolet light $A$, group $X$ secretory phospholipase $A 2$, several flavonoids, trans10, cis-12-conjugated linoleic acids (a group of polyunsaturated fatty acids), reduce the expression of $\operatorname{LXR} \alpha$, which in most cases is accompanied by a simultaneous downregulation of PPAR $\gamma^{24,42}$

Indirect evidence suggests that $L X R \alpha$ is regulated by PPAR $\gamma$ in human adipose tissue in vivo as well. Treatment of non-diabetic subjects with pioglitazone for 3 weeks resulted in a pronounced upregulation of LXR $\alpha$ mRNA expression. ${ }^{43}$ However, the regulation by PPAR $\gamma$ may be more complex as both PPAR $\gamma$ and its target genes, including the fatty acid-binding protein aP2, are in turn LXR $\alpha$ target genes in adipocytes. ${ }^{12,44}$ 
Previous studies reported that LXR activation during adipogenesis, potentiated fat accumulation in murine 3T3-L1 adipocytes and human fat cells. ${ }^{11,12}$ Conversely, siRNA-mediated inhibition of $\mathrm{LXR} \alpha$ suppressed adipocyte differentiation. ${ }^{12}$ The adipogenic effect of LXR was proposed to be dependent on PPAR $\gamma$ as LXR activation had no effect on adipogenesis in PPAR $\gamma-/$-mouse embryonic fibroblasts. ${ }^{12}$ However, the pro-adipogenic effects of LXR in 3T3-L1 and 3T3-442A cells have not been confirmed by other groups. ${ }^{45-47}$ It is worth pointing out that the studies showing positive effects also reported very low degree of differentiation in control cells and PPAR $\gamma$ agonists were not used in the differentiation medium. In contrast, the degree of adipocyte differentiation was high in the studies showing no or even negative effects of LXR. ${ }^{45,46}$ It is quite plausible that these differences as well as the presence or absence of PPAR $\gamma$ agonists could explain the discrepancies between the studies.

Taken together, in vitro data suggest that the activation of LXR might enhance adipogenesis at least when PPAR $\gamma$ is only partly activated. However, when PPAR $\gamma$ is fully activated, LXR has no additional effect on adipocyte differentiation and could possibly even suppress it. ${ }^{46}$ Therefore, LXR could act as a modulator of adipogenesis. The phenotype of LXR-/-mice (discussed below) also implies that LXR is not indispensable for murine adipogenesis. ${ }^{48,49}$

Whether LXR has a role in human adipogenesis, remains to be established. When human adipocytes are stimulated with GW3965 during late stages of in vitro differentiation, there are no effects on adipocyte morphology (Laurencikiene, unpublished observation) or on the expression of PPAR $\gamma$ and its target genes such as aP2. ${ }^{44,50}$

\section{LXR AND LIPID METABOLISM IN ADIPOCYTES}

\section{Cholesterol transport}

LXRs are well-defined regulators of cholesterol transport and metabolism in the liver, intestine and macrophages where they upregulate the expression of the cholesterol transporters ABCA1, ABCG1, $A B C G 5 / A B C G 8$, the rate-limiting enzyme in bile acid synthesis Cyp7A (in rodents, but not humans) and the high-density lipoproteinassociated apolipoprotein E (ApoE) (reviewed in Oosterveer et al. ${ }^{5}$ ).

Adipose tissue contains the largest depot of cholesterol in the body, ${ }^{15}$ which constitutes about $20 \%$ of the total intracellular cholesterol pool. This proportion can reach up to $50 \%$ in obesity. As cholesterol synthesis and catabolism are very low in fat cells, uptake and removal (that is, efflux via reverse cholesterol transport) are crucial for adipocyte turnover of cholesterol. Owing to the dynamic equilibrium between circulating and adipose cholesterol pools, adipose tissue can be considered as a 'buffering pool' important for whole body cholesterol homeostasis (reviewed in Yu BL et al. ${ }^{51}$ ).

In fat cells, LXR has been shown to upregulate the expression of several genes involved in cholesterol metabolism. In 3T3-442A adipocytes, endogenous or synthetic LXR agonists induce DNA binding to and activation of macrophage/adipocyte-specific enhancers in $A p o E_{1}^{52}$ an integral component in reverse cholesterol transport. In murine adipose tissue, upregulation of ApoE by PPAR $\gamma$ ligands depends on the presence of LXR. ${ }^{53}$ Other studies have confirmed the PPAR $\gamma$-LXR-ABCG1/ABCA1/ApoE axis of regulation. ${ }^{40,41,54,55}$ Moreover, niacin-induced cholesterol efflux in primary rat and 3T3-L1 adipocytes correlates with increased expression of LXR $\alpha^{56,57}$ In 3T3-L1 cells this is associated with increased mRNA expression of ABCA1. ${ }^{57}$ SR-B1, a protein mediating cholesterol exchange between cells and high-density lipoprotein particles is also upregulated by LXR ligands in 3T3-L1 adipocytes. ${ }^{58}$ The importance of LXR for the regulation of cholesterol transporters has been confirmed in murine knockout models (see below).

In human primary adipocytes, LXR regulates the expression of $A B C G 1$ and $A B C A 1 .{ }^{50}$ However, the role of these transporters in cholesterol efflux in human fat cells remains to be established.

\section{Lipogenesis}

LXR agonists are well-characterized inducers of hepatic lipogenesis (for review see Baranowski et al. ${ }^{6}$ ) where both endogenous and synthetic LXR agonists induce lipid accumulation via stimulation of SREBP-1C and its response genes encoding key lipogenic enzymes (for example, fatty acid synthase (FAS), stearoyl-CoA desaturase-1 (SCD1), Acyl Co-Carboxylase 1 (ACC1) and $\mathrm{aP2}$ ). ${ }^{16,59}$ The lipogenic properties of LXR have also been investigated in various other cell types, including adipocytes.

Treatment of murine 3T3-L1 adipocytes with 22(R)-oxycholesterol or T0901317 during differentiation, increased lipid accumulation and the expression of SREBP-1c and FAS mRNA. ${ }^{11,12}$ In addition, T0901317 upregulated the expression of both genes in murine adipose tissue in vivo. ${ }^{12}$

In contrast, subsequent studies, including results from our own laboratory, provide strong evidence that the regulation of lipogenesis in adipocytes differs from that in the liver. ${ }^{49,60,61}$ Sekiya et al. ${ }^{60}$ showed that although LXR induced SREBP-1C gene expression in white adipose tissue (WAT) of mice and rats, this was not accompanied with increased expression of FAS. In line with this, SREBP1c was neither recruited to the FAS promoter nor did it induce the activity of a FAS promoter-driven reporter gene in adipocytes. The discrepancies between the findings discussed above might depend on experimental conditions, including different glucose or insulin concentrations that are known to influence lipogenesis. In any case, the role of SREBP-1c in fat cell lipogenesis can be questioned by data from SREBP-1c -/- mice, as these animals develop diet-induced obesity similar to their wild-type littermates. ${ }^{61}$ Furthermore, both basal and insulin-stimulated lipogenesis are increased in mature adipocytes isolated from $\operatorname{LXR} \alpha \beta-/$ mice as compared with wild-type mice. ${ }^{49}$ Taken together, these data suggest that at least in rodent adipose tissue, LXR is not a primary regulator of lipogenesis.

Human adipocytes display very low rates of de novo lipogenesis. Stimulation of human primary adipocytes with LXR agonists for 7 days in culture has only marginal effects on the mRNA levels of SREBP-1C, FAS, ACC1 and SCD1. ${ }^{62}$ If a PPAR $\gamma$ agonist is included into the adipogenic medium, T0901317 has no additional effect on the expression of lipogenic genes. Moreover, although short (24 h) stimulation of in vitro-differentiated human adipocytes with GW3965 slightly but significantly upregulates SREBP-1c mRNA, other lipogenic genes such as FAS, SCD1, ACC1 or aP2 are not affected (see Liu et al. ${ }^{44}$, Stenson et al. ${ }^{50}$ and unpublished observations). It is therefore not likely that LXR has a strong impact on de novo lipogenesis in differentiated human adipocytes.

\section{Lipolysis}

Lipolysis, the enzymatic hydrolysis of triglycerides into free fatty acids and glycerol, is a pivotal process in adipocytes (reviewed in Lafontan and Langin ${ }^{63}$ ). LXRs have been implicated in lipolytic regulation in several studies. Over-expression and activation of $\mathrm{LXR} \alpha$ in murine 3T3-L1 adipocytes, upregulated basal but not hormone-stimulated release of free fatty acids. ${ }^{46}$ Administration of T0901317 to mice, increased serum free fatty acid and glycerol concentrations, suggesting increased adipocyte lipolysis. ${ }^{46}$ Similar treatments with GW3965 resulted in smaller fat cells, indicative of increased triglyceride utilization. ${ }^{64}$

We could recently show that activation of LXR increases basal lipolysis in human fat cells. Chromatin immunoprecipation demonstrated that GW3965 induced binding of LXR/RXR heterodimers to the promoter regions of the genes encoding perilipin (PLIN1) and hormone-sensitive lipase (HSL), resulting in the downregulation of the corresponding mRNA levels. ${ }^{50}$ PLIN1 and HSL are essential factors controlling lipolysis and the relative expression between these two proteins determines the lipolytic activity. ${ }^{63}$ Our data suggested that the increase in basal lipolysis caused by LXR was primarily dependent on the 
decreased expression of PLIN1. In agreement with this hypothesis, higher PLIN1 (as well as HSL) expression levels have been observed in WAT from LXR $\alpha \beta-/-$ mice when compared with wild-type littermates. $^{49}$

The role of LXR in regulating hormone-stimulated lipolysis is less clear. Although T0901317 treatments of 3T3-L1 adipocytes overexpressing $L X R \alpha$ did not change the maximal rate of free fatty acid or glycerol release upon stimulation with the $\beta 3$-adrenoceptor agonist, ${ }^{46}$ isolated murine $\mathrm{LXR} \alpha \beta-/$ - adipocytes displayed three times higher maximal response to noradrenalin stimulation when compared with fat cells from wild-type littermates. ${ }^{49}$ Treatments of human primary adipocytes with an LXR agonist influenced the expression of several genes regulating stimulated lipolysis. ${ }^{50}$

\section{Lipid oxidation}

LXRs have also been implicated in lipid oxidation, another intracellular pathway controlling lipid utilization. In hepatocytes, activation of LXR increased peroxisomal $\beta$-oxidation, ${ }^{65,66}$ whereas in myocytes LXR upregulated palmitate oxidation. ${ }^{67^{\prime}}$ Activation of LXR in 3T3-L1 adipocytes increased the expression of the fatty acid elongation enzyme Elovl $3{ }^{45}$ an enzyme present in brown adipocytes that is induced by exposure to cold conditions and the expression of which correlates with fatty acid oxidation. ${ }^{68}$ In agreement with this, studies in 3T3-L1 and human adipocytes have demonstrated that LXR activation shifts substrate oxidation toward utilization of lipids instead of carbohydrates. ${ }^{69}$ LXR agonist GW3965 upregulated the expression of pyruvate dehydrogenase kinase 4 (PDK4), which resulted in the inhibition of the pyruvate dehydrogenase complex, a central enzyme controlling substrate utilization.

In contrast to findings in white fat cells, both LXR isoforms have been implicated in the negative regulation of oxidation and energy expenditure in brown adipocytes. ${ }^{33,70}$ Thus, in murine brown adipocytes, LXR suppressed Elovl3 expression ${ }^{68}$ and, as mentioned previously, the LXR $\alpha /$ RIP140 complex suppresses the expression of UCP1 by preventing binding of PPAR $\gamma / P G C 1 \alpha^{33}$ These findings are supported by data obtained in the LXR knockout animals (see below).

In summary, these data suggest a cell-specific role for LXR in adipocyte substrate oxidation and energy dissipation. While activation of LXR seems to upregulate lipid oxidation in white fat cells (via PDK4, Elov3), it suppresses energy dissipation in brown adipocytes (via UCP1, Elov3).

\section{LXR AND GLUCOSE UPTAKE}

Glucose uptake in adipose tissue impacts on whole body glucose homeostasis. Two glucose transporters are responsible for glucose uptake in adipocytes. Glucose transproter-1 (Glut1) mediates basal glucose uptake, whereas Glut4 is mainly responsible for insulinstimulated glucose transport (reviewed in Muretta et al. ${ }^{71}$ ). Although several groups have studied the effects of LXR, there is no consensus on its role in adipose glucose transport. The first evidence that LXRs could regulate glucose uptake in fat cells was provided by Ross et al. ${ }^{46}$ Over-expression of LXR $\alpha$ in 3T3-L1 adipocytes combined with T0901317 stimulation led to increased basal glucose uptake, upregulation of Glut1 expression and increased glycogen synthesis while insulin-stimulated glucose transport was not affected.

In contrast, Laffitte et al. ${ }^{72}$ found that Glut4, but not Glut1 was upregulated by GW3965 in 3T3-L1 cells in vitro and in murine adipose tissue in vivo. Functional LXREs were found in both the murine and human Glut4 promoters (but were not reported in the Glut1 promoter). The LXR $\alpha /$ RXR dimer was shown to bind to these elements and to upregulate the activity of reporter constructs driven by Glut4 promoter. ${ }^{72,73}$ Short $(24 \mathrm{~h})$ treatments with T0901317 induced Glut4 expression in wild type, LXR $\alpha-/-$ and LXR $\beta-/$ - adipose tissue, but not in fat from $\operatorname{LXR} \alpha \beta-/-$ mice.
Somewhat unexpectedly, the increase in Glut4 expression was abolished after longer (7 days) treatments. ${ }^{73}$ Detailed analysis in different fat depots showed that Glut4 expression in epididymal fat was reduced in $L X R \alpha-/$ - mice, suggesting that $L X R \alpha$ might be required for basal activity of the Glut4 promoter. In line with the increased expression of glucose transporters, it has been reported that LXR upregulates both basal and insulin-stimulated glucose uptake in 3T3-L1 adipocytes. ${ }^{72,73}$ Taken together, the data discussed above suggest that LXR is a positive regulator of Glut4 and possibly Glut1 expression, and therefore of both insulinstimulated and basal glucose uptake.

In contrast, several subsequent studies have not been able to confirm these findings. In cultured primary brown adipocytes from rat fetuses, LXR selectively upregulated Glut4, but not Glut1 protein expression and cell membrane localization. ${ }^{74}$ Somewhat unexpectedly, basal but not insulin-stimulated glucose uptake was increased by T0901317 treatment in these cells, suggesting that mere expression of different glucose transporters on the cell membrane might not correlate with the rate and type of glucose transport. ${ }^{74}$ The same conclusion was drawn in another study showing that the upregulation of Glut4 by LXR in vivo in rat epididymal fat was not associated with an increase in insulin-stimulated glucose uptake. ${ }^{64}$ In two other in vivo studies, LXR activation lowered blood glucose, improved glucose tolerance and upregulated Glut4 expression only in adipose tissue from obese mice (ob/ob mice or dietinduced obese mice), but not in that from lean mice. ${ }^{72,75}$ Accordingly, lean transgenic mice overexpressing $L X R \alpha$ in adipose tissue (under the control of the aP2 promoter) displayed no changes in systemic glucose metabolism. ${ }^{76}$

Very few studies have addressed the role of LXR in regulating carbohydrate metabolism in human fat cells. In in vitro differentiated human SGBS adipocytes, T0901317 increased Glut4 mRNA levels by $50 \%$, although the effect on glucose uptake was not investigated. ${ }^{72}$

The discrepancies between the studies discussed above could be because of differences in agonists, in vitro cell models, treatment conditions as well as differences in age, weight and genotype of the mouse strains. In any case, it is apparent that the effect of LXR on the expression of glucose transporters and glucose uptake in adipocytes and adipose tissue is dependent on the metabolic and intracellular context. Therefore, the role of LXR in modulating glucose transport remains to be established.

\section{LXR AND INFLAMMATION IN ADIPOSE TISSUE}

Obesity is coupled to a chronic low-grade inflammatory state in WAT, characterized by the production of pro-inflammatory cytokines as well as infiltration and activation of macrophages, which affects systemic and local insulin sensitivity (reviewed in Ouchi et $a l^{77}$ ). Studies in rodents and different cell systems suggest that LXR is an important regulator of cytokine production in both adipocytes and macrophages.

\section{LXR and inflammation in macrophages}

LXR suppresses a pro-inflammatory phenotype in macrophages by repressing a set of inflammatory genes induced by either LPS, TNF- $\alpha$ or IL- $1 \beta .^{78}$ This was suggested to be because of LXR's ability to interfere with NF- $\kappa B$ signaling in the nucleus. ${ }^{79}$ Subsequent studies confirmed that SUMOylated, ligand-bound LXR, NR co-repressor and SMRT formed a complex that interfered with the DNA-binding ability of NF- $\kappa \mathrm{B}$, a central regulator of inflammatory pathways. ${ }^{36,78-80}$ Moreover, in macrophages there is a cross talk between LXR and toll-like receptors (TLRs). LXR is known to directly regulate TLR4 ${ }^{81}$ which could constitute another mechanism through which LXR attenuates inflammatory responses. Whether any of these effects are present in human macrophages in adipose tissue is not known. 


\section{LXR and inflammation in adipocytes}

The anti-inflammatory role of LXR in macrophages has prompted investigations into the cross talk between LXR and inflammatory cytokines in fat cells. Activation of LXR by a synthetic agonist fully restored insulin sensitivity in TNF- $\alpha$-treated primary brown adipocytes. ${ }^{74}$ This effect was mediated by the inhibition of protein tyrosine phosphatase 1B (PTP1B) production and restoration of the insulin-signaling cascade. Similar results were obtained in studies using the human liposarcoma cell line LiSa-2 that is able to differentiate into white adipocyte-like cells. ${ }^{82}$ This cell line develops insulin resistance in the final stages of differentiation. In these cells, T0901317 restored insulin sensitivity and insulininduced Akt phosphorylation, which was accompanied by reduced expression of IL- 6 and MCP- $1 .{ }^{83}$ Furthermore, in LiSa-2 cells and human visceral adipocytes, T091317 and GW3965 counteracted insulin resistance and IL- 6 secretion induced by TNF- $\alpha$, which was mediated by attenuated JNK1/2 activity. ${ }^{84}$

In addition to cytokines, LXR is a potential regulator of adiponectin and resistin. In vivo treatment of mice with T091317 resulted in a minor (20-50\%) upregulation of resistin and adiponectin mRNA. ${ }^{72}$ Slight upregulation of adiponectin mRNA by T0901317 was also observed in human Chub-S7 adipocytes, but not in the stroma-vascular fraction of human adipose tissue. ${ }^{62}$ Clustering analysis of hypocaloric diet-regulated genes in human adipose tissue suggested that $\mathrm{LXR} \alpha$ might regulate the expression of adiponectin receptors. ${ }^{85}$ Yet, there is so far no strong experimental evidence indicating that LXR is an important regulator of adiponectin expression.

Taken together, these data suggest that although LXR may not have a major role in over-all adipokine secretion, it could attenuate the release of inflammatory cytokines in fat cells and possibly in adipose tissue macrophages.

\section{OTHER INTRACELLULAR PATHWAYS AFFECTED BY LXR IN ADIPOCYTES}

Activation of LXRs in murine 3T3-L1 cells and in primary brown adipocytes reduces the expression and the activity of $11 \beta$ hydroxysteroid dehydrogenase type $1(11 \beta-H S D 1),{ }^{86}$ an effect which is abolished in LXR $\alpha \beta-/-$ mice. $11 \beta$-HSD1 converts inactive corticosteroids into biologically active glucocorticoids, such as cortisol, suggesting that LXR might interfere with peripheral glucocorticoid activation.

LXR could also have a role in vascularization of adipose tissue. This notion is based on the findings showing that LXR activation induces the expression of vascular endothelial growth factor in murine and human macrophages as well as in murine adipose tissue in vivo. ${ }^{87}$ It has consequently been speculated that LXRs might counteract adipose tissue hypoxia in obesity.

\section{FACTORS REGULATING LXR EXPRESSION}

Apart from pro-adipogenic factors, LXR expression and activity is regulated by a number of other mediators. The promoter of $\operatorname{LX} \alpha$ contains LXREs, enabling an autoregulatory loop in adipocytes and macrophages. ${ }^{88}$ This may be important for the induction of LXR above a threshold necessary to regulate certain target genes.

Several steroid hormones affect LXR expression. Glucocorticoid treatment of in vitro-differentiated human subcutaneous and visceral adipocytes from severely obese subjects, induced the expression of 22 transcription factors, which included LXR. ${ }^{89}$ However, whether this was mediated by direct or indirect regulation of the LXR genes is not clear. Estrogen (17 $\beta$-estradiol) suppresses the activity of $L X R \alpha$ promoter-reporter constructs in 3T3-L1 cells as well as LXR $\alpha$ expression in murine adipocytes. ${ }^{90}$

The expression of LXR in mouse WAT is downregulated by several pro-inflammatory factors, including LPS, TNF $\alpha$ and IL $1 \beta .^{91}$
TNF $\alpha$ has been shown to downregulate the expression of $L X R \alpha$ and LXR $\beta$ in differentiated 3T3-L1 adipocytes and to suppress the activity of LXRE-driven reporter constructs. ${ }^{91}$

In brown adipocytes and white fat cells expressing brown adipocyte-like features (inguinal fat), the expression of LXR and its target gene SREBP-1C is induced by cold exposure and $\beta$-adrenoceptor agonists, stimuli, which upregulate intracellular cAMP levels. ${ }^{92}$ This finding might seem at odds with previously discussed data showing that LXR activation suppresses UCP1 expression in adipocytes. ${ }^{33,93}$ However, it has been proposed in other cell types that LXR in its non-ligand-bound form might act as a cAMP-responsive transcription factor, regulating a different set of genes than those affected by oxysterol-activated LXR. ${ }^{94}$ Whether this mechanism bears any relevance in white adipose tissue remains to be established.

\section{ADIPOSE PHENOTYPE OF LXR $\alpha$, LXR $\beta$ AND LXR $\alpha / \beta$ KNOCKOUT MICE}

Isoform-specific (LXR $\alpha-/-$ and LXR $\beta-/-)$ and double (LXR $\alpha \beta-/-)$ knockout mice have been produced by two different laboratories. 95-97 For LXR $\alpha \beta-/-$, both strains are glucose tolerant and insulin sensitive, and display 15-20\% smaller adipose tissue depots than wild-type littermates. ${ }^{11,61}$ The relative difference in adipose depot size compared with wild-type littermates increases with age. In addition, LXR $\alpha \beta-/-$ mice are resistant to diet-induced obesity and have significantly smaller adipocytes than wild-type littermates. ${ }^{48,61,98}$ This could depend on attenuated adipogenesis, lipogenesis and/or increased fat utilization (lipolysis and/or lipid oxidation). In favor of the latter hypothesis is the finding that the LXR $\alpha \beta-/-$ mice generated by the Mangelsdorf laboratory show high expression of UCP1 in white adipose tissue and muscle, which results in high energy expenditure. ${ }^{33,61}$ It has therefore been suggested that increased oxidation in adipose tissue and muscle constitutes at least a part of the mechanism protecting these mice from diet-induced obesity. In contrast, the LXR $\alpha \beta-/$ strain developed in the Gustafsson laboratory shows increased expression of UCP1 in brown, ${ }^{70}$ but not in white adipose tissue. ${ }^{98}$

Conflicting results have been published regarding the endocrine function of adipocytes in LXR $\alpha \beta-/-$ mice. Thus, while one study reported a $50 \%$ reduction in leptin mRNA and no increase upon high fat diet, ${ }^{48}$ another group using another mouse strain demonstrated that leptin concentrations were increased by $80 \%$ in the knockout mice. ${ }^{98}$

The differences observed in these two strains could be explained by different genetic backgrounds including possible differences in the infiltration of brown or brown-like adipocytes in specific WAT depots. ${ }^{49,98}$ In any case, despite tissue-specific differences in gene and protein expression, both strains of $\mathrm{LXR} \alpha \beta-/$ - mice are likely to be protected against diet-induced obesity through increased metabolic rate.

The adipose tissue phenotype in LXR knockout animals has also contributed to the understanding of LXR function in specific tissues. Different sets of genes are affected by the absence of LXR in the liver or white and brown adipose tissue. ${ }^{93}$ For example, LXR is required for basal expression of SREBP-1c in the liver but not in adipose tissue, suggesting that LXR may regulate lipogenesis via different mechanisms in adipocytes and hepatocytes. ${ }^{49,99}$

Selective knockouts of LXR isoforms have confirmed that while some of LXR functions are redundant and can be mediated by both isoforms, others are unique and specific for LXR $\alpha$ or LXR $\beta$. Gene expression profiling in gonadal WAT of wild type, LXR $\alpha-/$ and LXR $\beta-/$ - mice showed that 443 genes were increased and 397 genes were decreased in LXR $\alpha-/-$, while 155 genes were increased and 328 gene were decreased in LXR $\beta-/$ - animals compared with wild-type littermates. ${ }^{100}$ Gene ontology analysis revealed that genes coding for cytokines were preferentially regulated in LXR $\beta-/$ - mice, whereas genes involved in 
carbohydrate metabolism seemed to be more $\mathrm{LXR} \alpha$ specific. Genes belonging to lipid/cholesterol metabolism were equally affected in both mice strains. ${ }^{100}$ Other studies have confirmed these findings. Thus, SREBP-1C, cholesterol transproters ABCG1 and $A B C A 1$ were similarly regulated by $L X R$ agonists in adipose tissue of both LXR $\alpha-/$ - and LXR $\beta-/-$ mice. ${ }^{73,88}$ On the other hand, LXR $\beta$-/- mice were resistant to diet-induced obesity, had small fat cells and impaired fat storage in adipocytes. ${ }^{48,98}$ Despite displaying a lean phenotype, LXR $\beta-/$ - mice became insulin resistant on a high fat diet. ${ }^{48,98}$ In contrast, $\operatorname{LXR} \alpha-/-$ mice accumulated visceral and subcutaneous fat on a high fat diet to a degree comparable with wild-type littermates. However, LXR $\alpha-/$-animals remained insulin sensitive even on a high fat diet. ${ }^{33,48,98}$

Adipose tissue-specific LXR knockout mice have not yet been generated. It is therefore difficult to identify the primary and secondary effects related to the absence of LXR in adipose tissue. Nevertheless, LXR knockout models have contributed to the understanding of how LXR isoforms as well as LXR in general may affect adipose function. Figure 1 and Table 1 summarize the reported roles of LXR (including $\alpha$ - and $\beta$-specific effects) in different adipose cell types.

\section{IMPACT OF LXR ACTIVATION IN METABOLIC DISEASES IN ANIMAL MODELS}

A number of findings in animal models suggest that LXR activation could have a role in the treatment of common metabolic disorders, including hyperlipidemia, atherosclerosis and diabetes. In rodents, treatment with different LXR agonists reduces serum and hepatic cholesterol levels, ${ }^{97}$ inhibits atherosclerosis ${ }^{101-103}$ and improves glucose tolerance. ${ }^{47,72,75}$ In most of these studies, the reported outcomes are primarily mediated by effects in non-adipose tissues. However, it should be noted that both T0901317 and GW3965 have been shown to increase serum and hepatic triglyceride levels, suggesting that these specific compounds may not be suitable for further clinical development. The development of isoform-specific or partial LXR ligands is an attractive possibility for new therapeutic agents. LXR $\beta$-specific agonists are suggested to mediate antiinflammatory effects and have beneficial influence on cholesterol metabolism without increasing hepatic lipogenesis. In addition, some partial LXR agonists lacking effects on hepatic lipogenesis have been developed. ${ }^{103-105}$ The effects of these agonists in adipose tissue have not yet been investigated. The so far limited in vitro data from human macrophages and adipocytes support the notion that LXR $\beta$ stimulation may be preferred in a clinical setting because of its anti-inflammatory effects in macrophages and the fact that $L X R \alpha$ activation stimulates fat cell lipolysis-a wellestablished risk factor for insulin resistance.

ROLE OF LXR IN HUMAN OBESITY AND INSULIN RESISTANCE A possible involvement of dysregulated LXR signaling in human obesity has been proposed in several independent studies. For example, the relative levels of LXR $\alpha$ in subcutaneous WAT were

Table 1. Summary of studies on LXR function in adipocytes

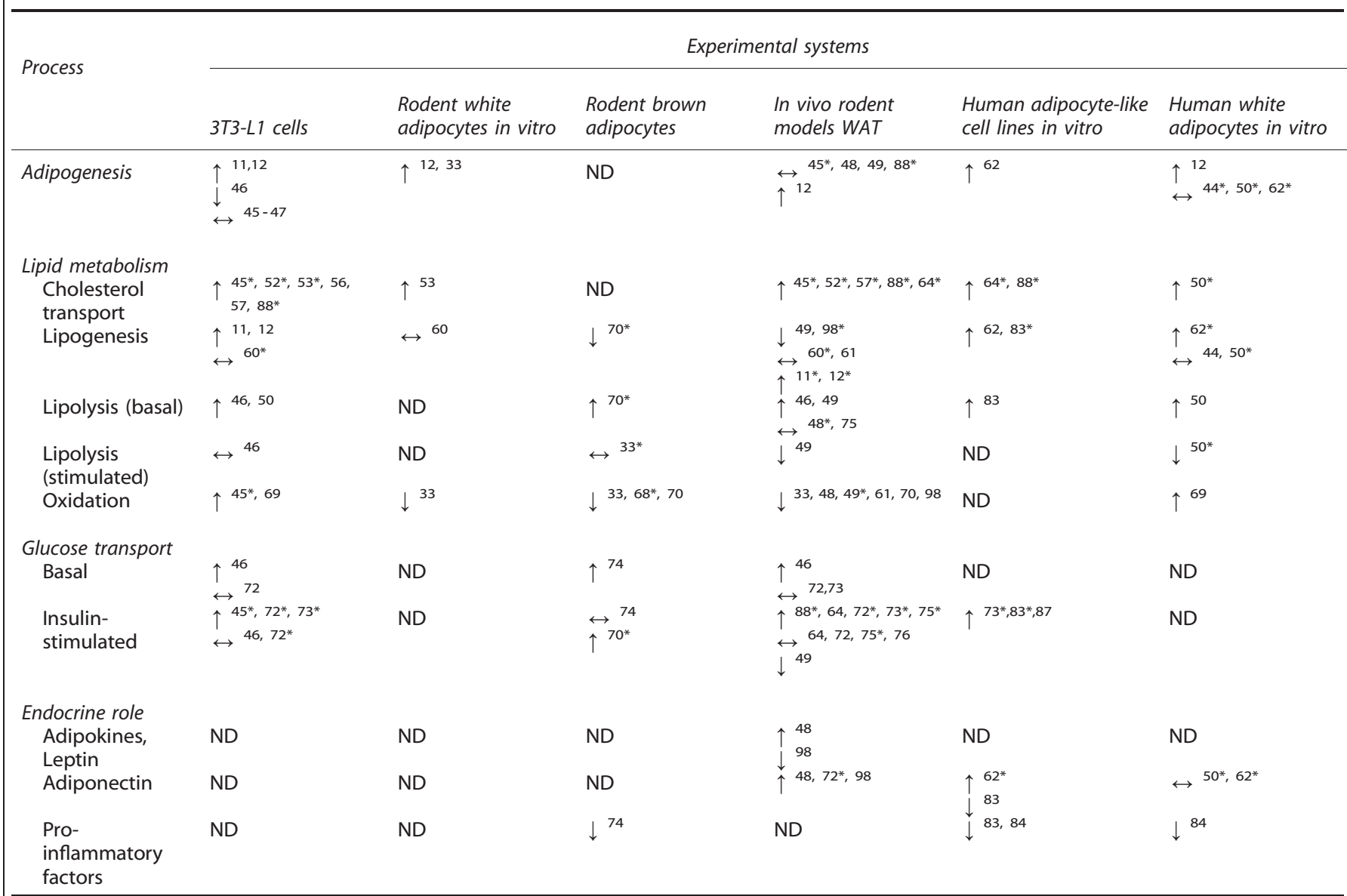

Abbreviations: $L X R$, liver $X$ receptor; ND, not determined. The reported role of LXR as an activator ( $\uparrow$ ) or suppressor $(\downarrow)$ of intracellular processes in different adipose experimental systems. References demonstrating no effect of LXR are indicated by $(\leftrightarrow)$. ${ }^{*}$ Denotes that effects have only been demonstrated at the mRNA level. 
higher in a cohort of obese compared with age-matched lean women. Moreover, a SNP (rs2279238) and a haplotype of LXR $\alpha$ as well as two SNPs (LB44732G $>A$ and rs2695121) in LXR 3 were associated with obesity in the same cohort. ${ }^{9}$ A SNP ( $r$ 17373080) in the promoter region of LXR $\beta$ was associated with type 2 diabetes in a Norwegian cohort and with obesity/overweight in French and European cohorts. ${ }^{8,10}$ However, in vitro studies have not been able to demonstrate any functional impact of the latter SNP on promoter activity. ${ }^{8}$ In addition to genetic polymorphisms, expression of two LXR co-regulators (CIDEA and RIP-140) is downregulated in obese adipose tissue, which could result in altered LXR signaling. ${ }^{106,107}$

Although data from murine models discussed above suggest that adipose tissue-specific treatments with LXR agonist could have several beneficial effects, including enhanced reverse cholesterol transport, increased glucose uptake, attenuated release of pro-inflammatory factors, increased lipid oxidation and reduced atherosclerosis, data on the systemic effects of LXR agonists in humans are lacking. To date, there is only one published study in humans, a phase 1 study that determined the effect of a nonisoform-specific LXR agonist. ${ }^{108}$ The agent increased ABCG1 and ABCA1 mRNA in peripheral blood cells, but $55 \%$ of the subjects experienced neurological side effects, which could be because of the fact that LXR is expressed in the brain. This implies that an agonist for clinical use should not pass the blood-brain barrier. At present, there are no on-going clinical trials on LXR modulators, at least not reported in the US National Institutes of Health database (http://ww.clinicaltrials.gov). There could be many reasons for this. The integrated effect of LXR activation is dependent on the action in many organs, particularly in the liver. The positive actions of LXR on reverse cholesterol transport and hepatic gluconeogenesis could be counteracted by increased hepatic lipogenesis and adipocyte lipolysis, two processes promoting hyperlipidemia and insulin resistance. This demonstrates that LXR activation can have both positive and negative effects on metabolic parameters. Moreover, the fact that LXR shares its heterodimerizing partner (that is, RXR) with peroxisome proliferated activate receptors (PPARs) and sometimes competes for the same DNA-response elements, suggests that LXR activation could also affect PPAR signaling. Taken together, all these factors could lead to unexpected consequences when administering LXR activators in vivo. It is also important to note that the action of LXR appears to be species specific, making it difficult to translate data in animal models to a clinical situation. For example, LXR agonists have been reported to induce differential effects in primary rat versus human hepatocytes. ${ }^{109}$ Similar studies comparing primary human and murine adipocytes are so far lacking.

In summary, given the scant data in human model systems, it is obvious that more studies are required to elucidate the effects of LXR in different tissues, the interactions between these effects and the outcome at the whole body level.

\section{CONFLICT OF INTEREST}

The authors declare no conflict of interest.

\section{REFERENCES}

1 McEwan IJ. Nuclear receptors: one big family. Methods Mol Biol 2009; 505: 3 - 18.

2 Perez E, Bourguet W, Gronemeyer $\mathrm{H}$, de Lera AR. Modulation of RXR function through ligand design. Biochim Biophys Acta 2011; 1821: 57-69.

3 Schroepfer Jr GJ. Oxysterols: modulators of cholesterol metabolism and other processes. Physiol Rev 2000; 80: 361 - 554.

4 Viennois E, Pommier AJ, Mouzat K, Oumeddour A, El Hajjaji FZ, Dufour J et al. Targeting liver $X$ receptors in human health: deadlock or promising trail? Expert Opin Ther Targets 2011; 15: 219-232.

5 Oosterveer MH, Grefhorst A, Groen AK, Kuipers F. The liver X receptor: control of cellular lipid homeostasis and beyond Implications for drug design. Prog Lipid Res 2010; 49: $343-352$.
6 Baranowski M. Biological role of liver X receptors. J Physiol Pharmacol 2008; 59: $31-55$.

7 Seol W, Choi HS, Moore DD. Isolation of proteins that interact specifically with the retinoid X receptor: two novel orphan receptors. Mol Endocrinol 1995; 9: 72 - 85.

8 Dahlman I, Nilsson M, Gu HF, Lecoeur C, Efendic S, Ostenson CG et al. Functional and genetic analysis in type 2 diabetes of liver $\mathrm{X}$ receptor alleles--a cohort study. BMC Med Genet 2009; 10: 27.

9 Dahlman I, Nilsson M, Jiao H, Hoffstedt J, Lindgren CM, Humphreys K et al. Liver $\mathrm{X}$ receptor gene polymorphisms and adipose tissue expression levels in obesity. Pharmacogenet Genomics 2006; 16: 881 - 889.

10 Solaas K, Legry V, Retterstol K, Berg PR, Holven KB, Ferrieres J et al. Suggestive evidence of associations between liver $\mathrm{X}$ receptor beta polymorphisms with type 2 diabetes mellitus and obesity in three cohort studies: HUNT2 (Norway), MONICA (France) and HELENA (Europe). BMC Med Genet 2010; 11: 144.

11 Juvet LK, Andresen SM, Schuster GU, Dalen KT, Tobin KA, Hollung K et al. On the role of liver X receptors in lipid accumulation in adipocytes. Mol Endocrinol 2003; 17: $172-182$.

12 Seo JB, Moon HM, Kim WS, Lee YS, Jeong HW, Yoo EJ et al. Activated liver X receptors stimulate adipocyte differentiation through induction of peroxisome proliferator-activated receptor gamma expression. Mol Cell Biol 2004; 24: $3430-3444$.

13 Steffensen KR, Schuster GU, Parini P, Holter E, Sadek CM, Cassel T et al. Different regulation of the LXRalpha promoter activity by isoforms of CCAAT/enhancerbinding proteins. Biochem Biophys Res Commun 2002; 293: $1333-1340$.

14 Chen M, Beaven S, Tontonoz P. Identification and characterization of two alternatively spliced transcript variants of human liver $X$ receptor alpha. J Lipid Res 2005; 46: 2570-2579.

15 Krause BR, Hartman AD. Adipose tissue and cholesterol metabolism. J Lipid Res 1984; 25: $97-110$.

16 Schultz JR, Tu H, Luk A, Repa JJ, Medina JC, Li L et al. Role of LXRs in control of lipogenesis. Genes Dev 2000; 14: $2831-2838$

17 Collins JL, Fivush AM, Watson MA, Galardi CM, Lewis MC, Moore LB et al. Identification of a nonsteroidal liver $X$ receptor agonist through parallel array synthesis of tertiary amines. J Med Chem 2002; 45: 1963-1966.

18 Madsen L, Petersen RK, Steffensen KR, Pedersen LM, Hallenborg P, Ma T et al. Activation of liver $X$ receptors prevents statin-induced death of 3T3-L1 preadipocytes. J Biol Chem 2008; 283: 22723-22736.

19 Houck KA, Borchert KM, Hepler CD, Thomas JS, Bramlett KS, Michael LF et al. T0901317 is a dual LXR/FXR agonist. Mol Genet Metab 2004; 83: $184-187$.

20 Mitro N, Vargas L, Romeo R, Koder A, Saez E. T0901317 is a potent PXR ligand: implications for the biology ascribed to LXR. FEBS Lett 2007; 581: $1721-1726$.

21 Rizzo G, Disante M, Mencarelli A, Renga B, Gioiello A, Pellicciari R et al. The farnesoid $X$ receptor promotes adipocyte differentiation and regulates adipose cell function in vivo. Mol Pharmacol 2006; 70: 1164-1173.

22 Li X, Yeh V, Molteni V. Liver X receptor modulators: a review of recently patented compounds (2007-2009). Expert Opin Ther Pat 2010; 20: 535-562.

23 Madsen L, Petersen RK, Kristiansen K. Regulation of adipocyte differentiation and function by polyunsaturated fatty acids. Biochim Biophys Acta 2005; 1740: $266-286$.

24 Li X, Shridas P, Forrest K, Bailey W, Webb NR. Group X secretory phospholipase A2 negatively regulates adipogenesis in murine models. FASEB J 2010; 24 $4313-4324$.

$25 \mathrm{Hu}$ X, Li S, Wu J, Xia C, Lala DS. Liver X receptors interact with corepressors to regulate gene expression. Mol Endocrinol 2003; 17: 1019-1026.

26 Phelan CA, Weaver JM, Steger DJ, Joshi S, Maslany JT, Collins JL et al. Selective partial agonism of liver $\mathrm{X}$ receptor alpha is related to differential corepressor recruitment. Mol Endocrinol 2008; 22: 2241 - 2249.

27 Yu C, Markan K, Temple KA, Deplewski D, Brady MJ, Cohen RN. The nuclear receptor corepressors NCoR and SMRT decrease peroxisome proliferator-activated receptor gamma transcriptional activity and repress 3T3-L1 adipogenesis. J Biol Chem 2005; 280: 13600-13605.

28 Brendel C, Schoonjans K, Botrugno OA, Treuter E, Auwerx J. The small heterodimer partner interacts with the liver $X$ receptor alpha and represses its transcriptional activity. Mol Endocrinol 2002; 16: 2065-2076.

29 Tabbi-Anneni I, Cooksey R, Gunda V, Liu S, Mueller A, Song G et al. Overexpression of nuclear receptor SHP in adipose tissues affects diet-induced obesity and adaptive thermogenesis. Am J Physiol Endocrinol Metab 2010; 298: E961-E970.

30 Kulyte A, Pettersson AT, Antonson P, Stenson BM, Langin D, Gustafsson JA et al. CIDEA interacts with liver $X$ receptors in white fat cells. FEBS Lett 2011; 585: $744-748$.

31 Jakobsson T, Osman W, Gustafsson JA, Zilliacus J, Warnmark A. Molecular basis for repression of liver $X$ receptor-mediated gene transcription by receptorinteracting protein 140. Biochem J 2007; 405: 31 - 39. 
32 Herzog B, Hallberg M, Seth A, Woods A, White R, Parker MG. The nuclear receptor cofactor, receptor-interacting protein 140 , is required for the regulation of hepatic lipid and glucose metabolism by liver X receptor. Mol Endocrinol 2007; 21: $2687-2697$.

33 Wang $\mathrm{H}$, Zhang $\mathrm{Y}$, Yehuda-Shnaidman E, Medvedev AV, Kumar N, Daniel KW et al. Liver $X$ receptor alpha is a transcriptional repressor of the uncoupling protein 1 gene and the brown fat phenotype. Mol Cell Biol 2008; 28: 2187-2200.

34 Oberkofler $\mathrm{H}$, Schraml E, Krempler F, Patsch W. Potentiation of liver X receptor transcriptional activity by peroxisome-proliferator-activated receptor gamma co-activator 1 alpha. Biochem J 2003; 371: 89-96.

35 Jakobsson T, Venteclef N, Toresson G, Damdimopoulos AE, Ehrlund A, Lou X et al. GPS2 is required for cholesterol efflux by triggering histone demethylation, LXR recruitment, and coregulator assembly at the ABCG1 locus. Mol Cell 2009; 34: 510-518.

36 Venteclef N, Jakobsson T, Ehrlund A, Damdimopoulos A, Mikkonen L, Ellis E et al. GPS2-dependent corepressor/SUMO pathways govern anti-inflammatory actions of LRH-1 and LXRbeta in the hepatic acute phase response. Genes Dev 2010; 24: $381-395$.

37 Li X, Zhang S, Blander G, Tse JG, Krieger M, Guarente L. SIRT1 deacetylates and positively regulates the nuclear receptor LXR. Mol Cell 2007; 28: 91 - 106.

38 Ghisletti S, Huang W, Ogawa S, Pascual G, Lin ME, Willson TM et al. Parallel SUMOylation-dependent pathways mediate gene- and signal-specific transrepression by LXRs and PPARgamma. Mol Cell 2007; 25: 57-70.

39 Yamamoto T, Shimano H, Inoue N, Nakagawa Y, Matsuzaka T, Takahashi A et al. Protein kinase A suppresses sterol regulatory element-binding protein-1C expression via phosphorylation of liver $\mathrm{X}$ receptor in the liver. $J$ Biol Chem 2007; 282: 11687 - 11695 .

40 Chawla A, Boisvert WA, Lee $\mathrm{CH}$, Laffitte BA, Barak Y, Joseph SB et al. A PPAR gamma-LXR-ABCA1 pathway in macrophages is involved in cholesterol efflux and atherogenesis. Mol Cell 2001; 7: $161-171$.

41 Laffitte BA, Joseph SB, Walczak R, Pei L, Wilpitz DC, Collins JL et al. Autoregulation of the human liver $\mathrm{X}$ receptor alpha promoter. Mol Cell Biol 2001; 21: $7558-7568$.

42 Lee J, Jung E, Kim YS, Roh K, Jung KH, Park D. Ultraviolet A regulates adipogenic differentiation of human adipose tissue-derived mesenchymal stem cells via upregulation of Kruppel-like factor 2. J Biol Chem 2010; 285: 32647-32656.

43 Hammarstedt A, Sopasakis VR, Gogg S, Jansson PA, Smith U. Improved insulin sensitivity and adipose tissue dysregulation after short-term treatment with pioglitazone in non-diabetic, insulin-resistant subjects. Diabetologia 2005; 48: 96- 104.

44 Liu QY, Quinet E, Nambi P. Adipocyte fatty acid-binding protein (aP2), a newly identified LXR target gene, is induced by LXR agonists in human THP-1 cells. Mol Cell Biochem 2007; 302: $203-213$.

45 Hummasti S, Laffitte BA, Watson MA, Galardi C, Chao LC, Ramamurthy L et al. Liver $X$ receptors are regulators of adipocyte gene expression but not differentiation: identification of apoD as a direct target. J Lipid Res 2004; 45: 616-625.

46 Ross SE, Erickson RL, Gerin I, DeRose PM, Bajnok L, Longo KA et al. Microarray analyses during adipogenesis: understanding the effects of Wnt signaling on adipogenesis and the roles of liver $\mathrm{X}$ receptor alpha in adipocyte metabolism. Mol Cell Biol 2002; 22: 5989-5999.

47 Cao G, Liang Y, Broderick CL, Oldham BA, Beyer TP, Schmidt RJ et al. Antidiabetic action of a liver $X$ receptor agonist mediated by inhibition of hepatic gluconeogenesis. J Biol Chem 2003; 278: 1131 -1136.

48 Gerin I, Dolinsky VW, Shackman JG, Kennedy RT, Chiang SH, Burant CF et al. LXRbeta is required for adipocyte growth, glucose homeostasis, and beta cell function. J Biol Chem 2005; 280: 23024-23031.

49 Korach-Andre M, Archer A, Gabbi C, Barros RP, Pedrelli M, Steffensen KR et al. Liver-X Receptors regulate de novo lipogenesis in a tissue specific manner in C57BI/6 female mice. Am J Physiol Endocrinol Metab 2011; 301: E210-E222.

50 Stenson BM, Ryden M, Venteclef N, Dahlman I, Pettersson AM, Mairal A et al. Liver $X$ receptor (LXR) regulates human adipocyte lipolysis. J Biol Chem 2011; 286: $370-379$.

$51 \mathrm{Yu} \mathrm{BL}$, Zhao SP, Hu JR. Cholesterol imbalance in adipocytes: a possible mechanism of adipocytes dysfunction in obesity. Obes Rev 2010; 11: 560-567.

52 Laffitte BA, Repa JJ, Joseph SB, Wilpitz DC, Kast HR, Mangelsdorf DJ et al. LXRs control lipid-inducible expression of the apolipoprotein $\mathrm{E}$ gene in macrophages and adipocytes. Proc Natl Acad Sci USA 2001; 98: 507-512.

53 Yue L, Mazzone T. Peroxisome proliferator-activated receptor \{gamma\} stimulation of adipocyte ApoE gene transcription mediated by the liver receptor $X$ pathway. J Biol Chem 2009; 284: 10453 -10461.

54 Akiyama TE, Sakai S, Lambert G, Nicol CJ, Matsusue K, Pimprale S et al. Conditional disruption of the peroxisome proliferator-activated receptor gamma gene in mice results in lowered expression of $A B C A 1, A B C G 1$, and apoE in macrophages and reduced cholesterol efflux. Mol Cell Biol 2002; 22: 2607 - 2619.
55 Le Lay S, Robichon C, Le Liepvre X, Dagher G, Ferre P, Dugail I. Regulation of ABCA1 expression and cholesterol efflux during adipose differentiation of 3T3-L1 cells. J Lipid Res 2003; 44: 1499-1507.

56 Zhao SP, Yang J, Li J, Dong SZ, Wu ZH. Effect of niacin on LXRalpha and PPARgamma expression and HDL-induced cholesterol efflux in adipocytes of hypercholesterolemic rabbits. Int J Cardiol 2008; 124: 172-178.

$57 \mathrm{Wu}$ ZH, Zhao SP. Niacin promotes cholesterol efflux through stimulation of the PPARgamma-LXRalpha-ABCA1 pathway in 3T3-L1 adipocytes. Pharmacology 2009; 84: $282-287$.

58 Malerod L, Juvet LK, Hanssen-Bauer A, Eskild W, Berg T. Oxysterol-activated LXRalpha/RXR induces hSR-BI-promoter activity in hepatoma cells and preadipocytes. Biochem Biophys Res Commun 2002; 299: 916-923.

59 Yoshikawa T, Shimano H, Amemiya-Kudo M, Yahagi N, Hasty AH, Matsuzaka T et al. Identification of liver $X$ receptor-retinoid $X$ receptor as an activator of the sterol regulatory element-binding protein 1c gene promoter. Mol Cell Biol 2001; 21: $2991-3000$.

60 Sekiya M, Yahagi N, Matsuzaka T, Takeuchi Y, Nakagawa Y, Takahashi H et al. SREBP-1-independent regulation of lipogenic gene expression in adipocytes. J Lipid Res 2007; 48: 1581 - 1591.

61 Kalaany NY, Gauthier KC, Zavacki AM, Mammen PP, Kitazume T, Peterson JA et al. LXRs regulate the balance between fat storage and oxidation. Cell Metab 2005; 1: $231-244$.

62 Darimont C, Avanti O, Zbinden I, Leone-Vautravers P, Mansourian R, Giusti V et al. Liver $\mathrm{X}$ receptor preferentially activates de novo lipogenesis in human preadipocytes. Biochimie 2006; 88: 309-318.

63 Lafontan M, Langin D. Lipolysis and lipid mobilization in human adipose tissue. Prog Lipid Res 2009; 48: 275-297.

64 Commerford SR, Vargas L, Dorfman SE, Mitro N, Rocheford EC, Mak PA et al. Dissection of the insulin-sensitizing effect of liver $X$ receptor ligands. Mol Endocrinol 2007; 21: 3002-3012.

65 Beyer TP, Schmidt RJ, Foxworthy P, Zhang Y, Dai J, Bensch WR et al. Coadministration of a liver $\mathrm{X}$ receptor agonist and a peroxisome proliferator activator receptor-alpha agonist in Mice: effects of nuclear receptor interplay on high-density lipoprotein and triglyceride metabolism in vivo. J Pharmacol Exp Ther 2004; 309: $861-868$.

$66 \mathrm{Hu}$ T, Foxworthy P, Siesky A, Ficorilli JV, Gao H, Li S et al. Hepatic peroxisomal fatty acid beta-oxidation is regulated by liver $\mathrm{X}$ receptor alpha. Endocrinology 2005; 146: 5380-5387.

67 Kase ET, Thoresen GH, Westerlund S, Hojlund K, Rustan AC, Gaster M. Liver X receptor antagonist reduces lipid formation and increases glucose metabolism in myotubes from lean, obese and type 2 diabetic individuals. Diabetologia 2007; 50: $2171-2180$

68 Jakobsson A, Jorgensen JA, Jacobsson A. Differential regulation of fatty acid elongation enzymes in brown adipocytes implies a unique role for Elovl3 during increased fatty acid oxidation. Am J Physiol Endocrinol Metab 2005; 289: E517-E526.

69 Stenson BM, Ryden M, Steffensen KR, Wahlen K, Pettersson AT, Jocken JW et al. Activation of liver $\mathrm{X}$ receptor regulates substrate oxidation in white adipocytes. Endocrinology 2009; 150: 4104-4113.

70 Korach-Andre M, Archer A, Barros RP, Parini P, Gustafsson JA. Both liver-X receptor (LXR) isoforms control energy expenditure by regulating brown adipose tissue activity. Proc Natl Acad Sci USA 2011; 108: 403-408.

71 Muretta JM, Mastick CC. How insulin regulates glucose transport in adipocytes. Vitam Horm 2009; 80: 245-286.

72 Laffitte BA, Chao LC, Li J, Walczak R, Hummasti S, Joseph SB et al. Activation of liver $X$ receptor improves glucose tolerance through coordinate regulation of glucose metabolism in liver and adipose tissue. Proc Natl Acad Sci USA 2003; 100: 5419- 5424.

73 Dalen KT, Ulven SM, Bamberg K, Gustafsson JA, Nebb HI. Expression of the insulin-responsive glucose transporter GLUT4 in adipocytes is dependent on liver X receptor alpha. J Biol Chem 2003; 278: 48283 - 48291.

74 Fernandez-Veledo S, Nieto-Vazquez I, Rondinone CM, Lorenzo M. Liver X receptor agonists ameliorate TNFalpha-induced insulin resistance in murine brown adipocytes by downregulating protein tyrosine phosphatase-1B gene expression. Diabetologia 2006; 49: 3038-3048.

75 Grefhorst A, van Dijk TH, Hammer A, van der Sluijs FH, Havinga R, Havekes LM et al. Differential effects of pharmacological liver $X$ receptor activation on hepatic and peripheral insulin sensitivity in lean and ob/ob mice. Am J Physiol Endocrinol Metab 2005; 289: E829-E838.

76 Hong C, Walczak R, Dhamko H, Bradley MN, Marathe C, Boyadjian R et al. Constitutive activation of LXR in macrophages regulates metabolic and inflammatory gene expression: identification of ARL7 as a direct target. J Lipid Res 2011; 52: 531 - 539.

77 Ouchi N, Parker JL, Lugus JJ, Walsh K. Adipokines in inflammation and metabolic disease. Nat Rev Immunol 2011; 11: 85 -97. 
78 Joseph SB, Castrillo A, Laffitte BA, Mangelsdorf DJ, Tontonoz P. Reciprocal regulation of inflammation and lipid metabolism by liver $\mathrm{X}$ receptors. Nat Med 2003; 9: 213-219.

79 Castrillo A, Joseph SB, Marathe C, Mangelsdorf DJ, Tontonoz P. Liver X receptordependent repression of matrix metalloproteinase-9 expression in macrophages. J Biol Chem 2003; 278: 10443 - 10449.

80 Ghisletti S, Huang W, Jepsen K, Benner C, Hardiman G, Rosenfeld MG et al. Cooperative NCoR/SMRT interactions establish a corepressor-based strategy for integration of inflammatory and anti-inflammatory signaling pathways. Genes Dev 2009; 23: $681-693$.

81 Fontaine C, Rigamonti E, Nohara A, Gervois P, Teissier E, Fruchart JC et al. Liver X receptor activation potentiates the lipopolysaccharide response in human macrophages. Circ Res 2007; 101: 40-49.

82 Wabitsch M, Bruderlein S, Melzner I, Braun M, Mechtersheimer G, Moller P. LiSa-2 a novel human liposarcoma cell line with a high capacity for terminal adipose differentiation. Int J Cancer 2000; 88: 889-894.

83 Fernandez-Veledo S, Nieto-Vazquez I, de Castro J, Ramos MP, Bruderlein S, Moller $P$ et al. Hyperinsulinemia induces insulin resistance on glucose and lipid metabolism in a human adipocytic cell line: paracrine interaction with myocytes. J Clin Endocrinol Metab 2008; 93: 2866-2876.

84 Fernandez-Veledo S, Vila-Bedmar R, Nieto-Vazquez I, Lorenzo M. c-Jun Nterminal kinase $1 / 2$ activation by tumor necrosis factor-alpha induces insulin resistance in human visceral but not subcutaneous adipocytes: reversal by liver $X$ receptor agonists. J Clin Endocrinol Metab 2009; 94: 3583-3593.

85 Viguerie N, Vidal H, Arner P, Holst C, Verdich C, Avizou S et al. Adipose tissue gene expression in obese subjects during low-fat and high-fat hypocaloric diets. Diabetologia 2005; 48: $123-131$.

86 Stulnig TM, Oppermann U, Steffensen KR, Schuster GU, Gustafsson JA. Liver X receptors downregulate 11 beta-hydroxysteroid dehydrogenase type 1 expression and activity. Diabetes 2002; 51: $2426-2433$.

87 Walczak R, Joseph SB, Laffitte BA, Castrillo A, Pei L, Tontonoz P. Transcription of the vascular endothelial growth factor gene in macrophages is regulated by liver X receptors. J Biol Chem 2004; 279: 9905 - 9911.

88 Ulven SM, Dalen KT, Gustafsson JA, Nebb HI. Tissue-specific autoregulation of the LXRalpha gene facilitates induction of apoE in mouse adipose tissue. J Lipid Res 2004; 45: 2052 - 2062.

89 Lee MJ, Gong DW, Burkey BF, Fried SK. Pathways regulated by glucocorticoids in omental and subcutaneous human adipose tissues: a microarray study. Am $J$ Physiol Endocrinol Metab 2011; 300: E571-E580.

90 Lundholm L, Moverare S, Steffensen KR, Nilsson M, Otsuki M, Ohlsson C et al. Gene expression profiling identifies liver $X$ receptor alpha as an estrogenregulated gene in mouse adipose tissue. J Mol Endocrinol 2004; 32: 879-892.

91 Lu B, Moser AH, Shigenaga JK, Feingold KR, Grunfeld C. Type II nuclear hormone receptors, coactivator, and target gene repression in adipose tissue in the acutephase response. J Lipid Res 2006; 47: 2179-2190.

92 Hao Q, Hansen JB, Petersen RK, Hallenborg P, Jorgensen C, Cinti S et al. ADD1/ SREBP1c activates the PGC1-alpha promoter in brown adipocytes. Biochim Biophys Acta 2010; 1801: 421 - 429.

93 Stulnig TM, Steffensen KR, Gao H, Reimers M, Dahlman-Wright K, Schuster GU et al. Novel roles of liver $\mathrm{X}$ receptors exposed by gene expression profiling in liver and adipose tissue. Mol Pharmacol 2002; 62: 1299-1305.

94 Tamura K, Chen YE, Horiuchi M, Chen Q, Daviet L, Yang Z et al. LXRalpha functions as a CAMP-responsive transcriptional regulator of gene expression. Proc Natl Acad Sci USA 2000; 97: 8513-8518.
95 Peet DJ, Turley SD, Ma W, Janowski BA, Lobaccaro JM, Hammer RE et al. Cholesterol and bile acid metabolism are impaired in mice lacking the nuclear oxysterol receptor LXR alpha. Cell 1998; 93: 693-704.

96 Repa JJ, Liang G, Ou J, Bashmakov Y, Lobaccaro JM, Shimomura I et al. Regulation of mouse sterol regulatory element-binding protein-1c gene (SREBP-1c) by oxysterol receptors, LXRalpha and LXRbeta. Genes Dev 2000; 14: 2819-2830.

97 Alberti S, Schuster G, Parini P, Feltkamp D, Diczfalusy U, Rudling M et al. Hepatic cholesterol metabolism and resistance to dietary cholesterol in LXRbetadeficient mice. J Clin Invest 2001; 107: 565-573.

98 Korach-Andre M, Parini P, Larsson L, Arner A, Steffensen KR, Gustafsson JA. Separate and overlapping metabolic functions of LXRalpha and LXRbeta in C57BI/6 female mice. Am J Physiol Endocrinol Metab 2010; 298: E167-E178.

99 Ulven SM, Dalen KT, Gustafsson JA, Nebb HI. LXR is crucial in lipid metabolism. Prostaglandins Leukot Essent Fatty Acids 2005; 73: 59-63.

100 Steffensen KR, Nilsson M, Schuster GU, Stulnig TM, Dahlman-Wright K Gustafsson JA. Gene expression profiling in adipose tissue indicates different transcriptional mechanisms of liver $X$ receptors alpha and beta, respectively. Biochem Biophys Res Commun 2003; 310: 589- 593.

101 Joseph SB, McKilligin E, Pei L, Watson MA, Collins AR, Laffitte BA et al. Synthetic LXR ligand inhibits the development of atherosclerosis in mice. Proc Natl Acad Sci USA 2002; 99: 7604-7609.

102 Song C, Hiipakka RA, Liao S. Auto-oxidized cholesterol sulfates are antagonistic ligands of liver $\mathrm{X}$ receptors: implications for the development and treatment of atherosclerosis. Steroids 2001; 66: $473-479$

103 Kratzer A, Buchebner M, Pfeifer T, Becker TM, Uray G, Miyazaki M et al. Synthetic LXR agonist attenuates plaque formation in apoE-/- mice without inducing liver steatosis and hypertriglyceridemia. J Lipid Res 2009; 50: 312-326.

$104 \mathrm{Hu}$ B, Unwalla RJ, Goljer I, Jetter JW, Quinet EM, Berrodin TJ et al. Identification of phenylsulfone-substituted quinoxaline (WYE-672) as a tissue selective liver $\mathrm{X}$ receptor (LXR) agonist. J Med Chem 2010; 53: 3296-3304.

105 Quinet EM, Basso MD, Halpern AR, Yates DW, Steffan RJ, Clerin V et al. LXR ligand lowers LDL cholesterol in primates, is lipid neutral in hamster, and reduces atherosclerosis in mouse. J Lipid Res 2009; 50: 2358-2370.

106 Mejhert N, Laurencikiene J, Pettersson AT, Kaaman M, Stenson BM, Ryden M et al. Role of Receptor-Interacting Protein 140 in human fat cells. BMC Endocr Disord 2010; 10: 1

107 Nordstrom EA, Ryden M, Backlund EC, Dahlman I, Kaaman M, Blomqvist L et al. A human-specific role of cell death-inducing DFFA (DNA fragmentation factoralpha)-like effector A (CIDEA) in adipocyte lipolysis and obesity. Diabetes 2005; 54: $1726-1734$.

108 Katz A, Udata C, Ott E, Hickey L, Burczynski ME, Burghart P et al. Safety, pharmacokinetics, and pharmacodynamics of single doses of LXR-623, a novel liver X-receptor agonist, in healthy participants. J Clin Pharmacol 2009; 49 $643-649$

109 Kotokorpi P, Ellis E, Parini P, Nilsson LM, Strom S, Steffensen KR et al. Physiological differences between human and rat primary hepatocytes in response to liver $X$ receptor activation by 3-[3-[N-(2-chloro-3-trifluoromethylbenzyl)-(2,2-diphenylethyl)amino]propyl oxy]phenylacetic acid hydrochloride (GW3965). Mol Pharmacol 2007; 72: 947-955.

cc This work is licensed under the Creative Commons AttributionNonCommercial-No Derivative Works 3.0 Unported License. To view a copy of this license, visit http://creativecommons.org/licenses/by-nc-nd/3.0/ 